\title{
Knowledge and practices of critical care nurses regarding palliative care of cancer patients and suggestion for nursing guidelines booklet
}

\author{
Sousan Sayed Hassan, Khaled Mohamed Fares \& Mogedda Mohamed Mehany. \\ Clinical Nurse Specialist at Dierout Fever Hospital, Egypt. \\ Professor of Anesthesia, Intensive Care and Pain Management at Anesthesiology Department South, Cancer Institute \\ Assuit University, Egypt. \\ Lecturer of Critical Care Nursing Department, Faculty of Nursing, Assuit University, Egypt.
}

\begin{abstract}
Palliative care is care for patients with serious illness that focuses on relieving suffering and improving quality of life for patients and their families. Aim of the study: assess knowledge and practices of critical care nurses regarding palliative care of cancer patients, and suggest nursing guidelines booklet about palliative care for cancer patients. Sample: The study subjects consist of all available nursing staff (60) at medical intensive care unit (30), surgical intensive care (30) unit. Research design: Descriptive exploratory research design was used to conduct this study. Tools: Two tools were included nurses' structured interview sheet, and nurse observational checklist sheet. Results: the majority of studied nurses (97\%) had unsatisfactory knowledge scores regarding palliative care with Mean \pm SD $21 \pm 3.2$., more than half of studied nurses $(63.3 \%)$ had unsatisfactory level of practice regarding palliative care with Mean \pm SD $19.8 \pm 2.7$., there were no statistically significant relation between practices and knowledge. Conclusion: The majority of studied nurses (97\%) had unsatisfactory knowledge, as well more than half $(63 \%)$ of studied nurses had unsatisfactory level of practices regarding palliative care of patients with cancer Recommendations: Enrichment of all nurses about knowledge and practices related to palliative care will be helpful to achieve quality of life, and reading nursing guidelines booklet.
\end{abstract}

\section{Keywords: Palliative Care, Cancer, Families' Caregivers \& Nurses 'Knowledge.}

\section{Introduction}

Palliative care is a type of health care for patients and families facing life-threatening illness. Palliative care helps patients to achieve the best possible quality of life right up until the end of life. Palliative care can be provided at any time, to anyone with advanced illness, regardless of age. This type of care is focused on providing patients with relief from symptoms, pain and stress of a serious illness, Palliative care is provided by a team of doctors, nurses and other specialists who work with a patient's and other doctors to provide an extra layer of support. A palliative care team will help to develop a personal treatment plan, which may include medication and non-medicinal supports. (Canadian Virtual Hospice 2015, British Columbia Cancer Agency 2016)

Palliative care include the following principles: symptom management; advanced care planning; family-centered care; emotional; psychosocial; social and spiritual care; facilitating communication; awareness of ethical issues; and caring for the care giver. [Morton, Fontaine, (2013)]

Although hospice care has the same principles of comfort and support, palliative care is offered earlier in the disease process. As noted above, a person's cancer treatment continues to be administered and assessed while he or she is receiving palliative care. Hospice care is a form of palliative care that is given to a person when cancer therapies are no longer controlling the disease. It focuses on caring, not curing. When a person has a terminal diagnosis (usually defined as having a life expectancy of 6 months or less) and is approaching the end of life, he or she might be eligible to receive hospice care. [Carpenito, (2014)]

Person's cancer advances, he or she may experience a number of symptoms. These symptoms may include pain, loss of appetite, fatigue, weakness, weight loss, constipation, trouble breathing, confusion, nausea, vomiting, cough and a dry or sore throat. All of these symptoms can be managed with appropriate management. (Lewis et al., 2015)

Nurses play a significant role in palliative care. In addition to the conventional nursing duties of observing and recording symptoms and management, they also provide emotional support to cancer ill patients and their families, through a series of roles. (Nyakundi, 2013)

Nurses are given palliative care must first develop a relationship of trust to relate with patient and family member, promote hope for patient, pain and symptoms management by medication and nonpharmacological method as meditation, breathing exercise and skin care, maintain dignity and selfesteem by providing spiritual care, prevent feeling of 
isolation, use gentle touch during care, support family member provides information about home care services [Potter, et al., (2011)]

Nursing guidelines regarding palliative care for patients with cancer include assessing pain, planning pain-control regimen, and evaluating the effectiveness of therapies, management physical symptoms as nausea and vomiting, dyspnea, constipation, and mucositis through pharmacological and non-pharmacological management and providing suitable psychological and spiritual care (Nyakundi, 2013)

\section{Significance of the study}

Cancer is a process that begins with a small series of genetic changes within cells. It culminates in a lifechanging journey for patients involving family, friends, healthcare professionals, and ultimately, the entire healthcare system (Cancer Care Ontario, (2012).

Cancer is a global and international problem. It is the second leading cause of death worldwide after heart and vascular disease. More than twice as many people die from cancer than from AIDS, malaria, and tuberculosis combined. The World Health Organization (WHO) projects that without immediate action, the global number of deaths from cancer will increase by nearly $80 \%$ by 2030 , with most occurring in low- and middle-income countries. Research suggests that one-third of cancer deaths can be prevented. (International Agency for Research on Cancer, Globocan, (2012), Center of disease control \& prevention, (2014).

There were an estimated 14.1 million cancer cases around the world in 2012, of these 7.4 million cases were in men and 6.7 million in women. This number is expected to increase to 24 million by 2035 . (World cancer research fund international, 2013)

More than $60 \%$ of world's total new annual cases occur in Africa, Asia and Central and South America. These regions account for $70 \%$ of the world's cancer deaths (world health organization, 2014).

Statistics of South Egypt Cancer Institute at [2014] revealed that numbers of patients admitted to South Egypt Cancer Institute were 3282 patients (South Egypt Cancer Institute 2014).

\section{Aims of the study}

This study was conducted to

- Assess knowledge and practices of critical care nurses regarding palliative care of cancer patients at intensive care units at South Egypt Cancer Institute.

- Suggest nursing guidelines booklet about palliative car for cancer patients.

\section{Patients and methods Research design}

Descriptive exploratory research design was used to conduct this study.

\section{Research question}

- What is the level of knowledge and practices of critical care nurses regarding palliative care of patients with cancer at intensive care units at South Egypt Cancer Institute?

Setting

The present study was carried out at medical intensive care unit, surgical intensive care unit at South Egypt Cancer Institute.

\section{Subjects}

The study subjects consist of all available nursing staff at two previous mentioned setting who is assigned to provide care for patients with cancer. They compromised to 30 nurses at medical intensive care unit and 30 nurses at surgical intensive care unit at South Egypt Cancer Institute.

\section{Study tools}

Tools

Two tools were used in this study it developed by researcher based on the review of current literature these tool were designed and used for collecting data for this study.

First Tool: Nurse's knowledge assessment interview questionnaire sheet

It was constructed after reviewing relevant literature to assess nurses' knowledge regarding palliative care of cancer it includes 2 main parts as the following:

Part 1: personal data about nurses as age, sex, qualification, marital status, years of experience and attendance training program regarding palliative care. Part 2: questions related to knowledge of nurses about palliative care developed from (Morton, P.G., Fontaine, D.K., (2013), American cancer society, 2015).

It includes questions about:

- Definition and principles of palliative care.

- Pain and symptoms management.

- Psychological care

- Spiritual care

Scoring system of Nurse's knowledge assessment interview questionnaire sheet

For Multiple choice questions and true or false questions one grade for correct answer and zero for incorrect answer, for list questions, one grade for correct point and zero for incorrect point. Total numbers of question were 42 ; total numbers of grade were 46 , and categorized as

$<60 \%$ unsatisfactory

$\geq 60 \%$ satisfactory 


\section{Second Tool: Nurse's practices observational checklist}

This tool was conducted after reviewing the relevant literature and accordingly a modification was done to assess nurses' practice regarding palliative care of cancer it includes the following procedures:

- Pain assessment and management.

- Nursing care for nausea and vomiting.

- Nursing care for oral mucositis.

- Nursing care for dyspnea.

- Communication skills.

Scoring system of nurse's practices observational checklist

Each item was observed and categorized and scored into one grade for done and zero for not done total number of practice was 33, total number of grade were 33 , and categorized as

$<60 \%$ unsatisfactory

$\geq 60 \%$ satisfactory

Nursing guidelines booklet was designed after reviewing the relevant literatures and depend on knowledge and practices needs of nurses it includes the following:

- Definition and principles of palliative care

- Pain and symptoms management

- Psychological care

- Spiritual care of cancer patients

Methods

Technique for data collection:

The study was conducted throughout two main phases, which were preparatory phase, implementation phase.

\section{1-Prepatory phase}

This phase was involved:

Ethical consideration

- The research protocol was approved from Ethical Committee in the Faculty of Nursing.

- There was no risk for study subject during application of the research.

- The study was following common ethical principles in clinical research.

- Informed consent was obtained from nurses that are willing to participate in the study, after explaining the nature and purpose of the study.

- Confidentiality and anonymity was assured.

- Nurses had the right to refuse to participate or withdraw from the study without any rational at any time.

- Extensive review of literature.

- Official and non-official permissions to carry out the study was taken from the dean of South Egypt Cancer Institute, head of two previous mentioned setting , nurses to carry out this study.

- The tools were developed after extensive literature review.
- Content validity was established by panel of 5 experts who 3 experts at critical care nursing from faculty of nursing and 2 experts at intensive care from medical field at South Egypt Cancer Institute reviewed the instruments for clarity, relevance, comprehensiveness understanding, applicability and easiness for administer minor modification will be required.

- Reliability was estimated by Cronbach's Alpha for tool 1 nurses' knowledge assessment tool and its result was 0.79 , for tool 2 nurse skills assessment tool and its result was 0.87 .

- Pilot study:

- A pilot study was done on $10 \%$ of nurses from total sample and excluded from the study the aim of pilot study to test the clarity of the tools and to estimate the required time to fill the questionnaire based on the result of pilot study and any modification in the tools done.

\section{Implementation phase}

- Once permission was granted to proceed with the proposed study the researcher initiated data collection. The head nurse of the hospital department helped the researcher to accomplish this work.

- Data was collected at South Egypt Cancer Institute.

- At begging of interview the researcher was introduce herself to initiate line of communication.

- Interview questionnaire sheet: Filled after the purpose of the study was explained to the nurse prior to answering the question using tool one $\left[1^{\text {st }}\right.$ and $2^{\text {nd }}$ parts].

- An observational checklist was carried out during nurses giving care for cancer patient the researcher observed nurses practice in the morning and the afternoon shift (tool two).

- Data were collected at medical intensive care unit, surgical intensive care unit during the period from 1/4/2015:1/6/2015.

- Nursing guidelines booklet was designed depend on knowledge and practices needs of nurses.

- Each nurse obtained a copy of nursing guidelines booklet.

\section{Statistical design of data}

Data entry was done using compatible personal computer. The content of each tool analyzed, categorized, and then coded. Categorical variables were described by number and percent $(\mathrm{N}, \%)$, where continuous variables described by mean and standard deviation (Mean $\pm \mathrm{SD}$ ). Chi-square test used to compare between categorical variables where compare between continuous variables by t-test and Multivariate analysis. A two-tailed $p<0.05$ was considered statistically significant. All analyses were performed with the SPSS 20.0 software. 


\section{Results}

Table (1): Socio-demographic characteristics of studied nurses' $:($ no. $=60)$.

\begin{tabular}{|c|c|c|}
\hline Socio-demographic characteristics & No. & $\%$ \\
\hline \multicolumn{3}{|l|}{ Age } \\
\hline Range & \multicolumn{2}{|c|}{$20-40$} \\
\hline Mean+SD & \multicolumn{2}{|c|}{$26.2+5.1$} \\
\hline \multicolumn{3}{|l|}{ Age groups } \\
\hline $20: 30$ years & 49 & 81.7 \\
\hline$>30: 40$ years & 11 & 18.3 \\
\hline \multicolumn{3}{|l|}{ Sex } \\
\hline Male & 2 & 3.3 \\
\hline Female & 58 & 96.7 \\
\hline \multicolumn{3}{|l|}{ Marital status } \\
\hline Single & 11 & 18.3 \\
\hline Married & 49 & 81.7 \\
\hline \multicolumn{3}{|l|}{ Qualification } \\
\hline Bachelor & 11 & 18.3 \\
\hline Technical & 24 & 40.0 \\
\hline Diploma & 25 & 41.7 \\
\hline \multicolumn{3}{|l|}{ Years of experiences } \\
\hline Range & \multicolumn{2}{|c|}{$1-22$} \\
\hline Mean \pm SD & \multicolumn{2}{|c|}{$7.1+5.3$} \\
\hline $1-<5$ years & 27 & \\
\hline$\geq 5$ years & 33 & \\
\hline \multicolumn{3}{|c|}{ Do you get any training program about palliative care? } \\
\hline Yes & 0 & 0.0 \\
\hline $\mathrm{No}$ & 60 & 100.0 \\
\hline
\end{tabular}

Table (2): Mean score distribution of studied nurses' knowledge about palliative care of cancer patients :( no. $=60)$.

\begin{tabular}{|l|c|c|}
\hline \multicolumn{1}{|c|}{ Nurses knowledge } & Score & Mean+SD \\
\hline Definition of palliative care and its principles & 6 & $1 \pm 1$ \\
\hline Pain and symptoms' management & 33 & $15.8 \pm 2.6$ \\
\hline Pain management & 14 & $5.9 \pm 1.6$ \\
\hline Nausea and vomiting & 3 & $2 \pm 0.6$ \\
\hline Diarrhea and constipation & 5 & $2.8 \pm 0.9$ \\
\hline Mucositis & 5 & $3.1 \pm 1$ \\
\hline Dyspnea & 3 & $0.7 \pm 0.7$ \\
\hline Insomnia & 3 & $1.4 \pm 0.6$ \\
\hline Psychological issues & 3 & $2.3 \pm 0.7$ \\
\hline Spiritual issues & 4 & $1.9 \pm 0.9$ \\
\hline Total score of nurses' knowledge & 46 & $21 \pm 3.2$ \\
\hline Scoremed total grades for each item & & \\
\hline
\end{tabular}

Score mean total grades for each item 


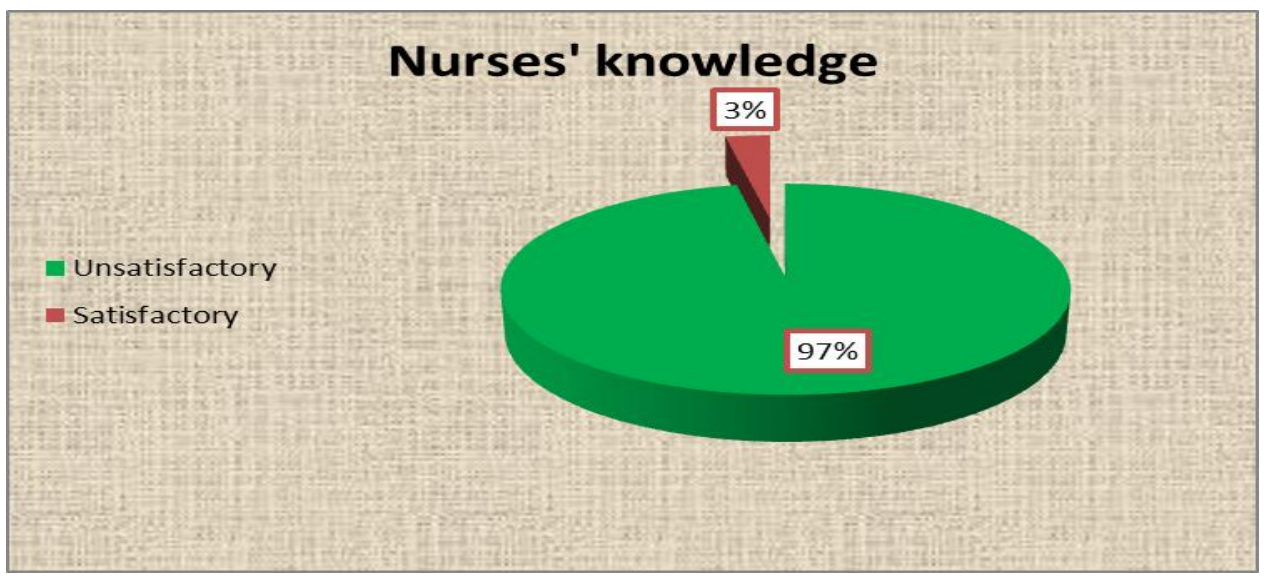

Figure (1): Percentages Distribution of nurses according to their total level of knowledge on palliative care

Table (3): Relation between nurses' level of knowledge regarding palliative care and socio-demographic characteristic.

\begin{tabular}{|c|c|c|c|c|}
\hline $\begin{array}{l}\text { socio-demographic } \\
\text { characteristic }\end{array}$ & $\begin{array}{c}\text { Knowledge level regarding } \\
\text { palliative care }\end{array}$ & Beta & $\mathbf{T}$ & P. value \\
\hline \multicolumn{5}{|l|}{ Age groups } \\
\hline $20-30$ years & $20.7 \pm 3.2$ & \multirow{2}{*}{0.052} & \multirow{2}{*}{0.374} & \multirow{2}{*}{0.710} \\
\hline $30-40$ years & $22.3 \pm 2.8$ & & & \\
\hline \multicolumn{5}{|l|}{ Sex } \\
\hline Male & $19 \pm 1.4$ & \multirow[b]{2}{*}{0.102} & \multirow{2}{*}{0.819} & \multirow[t]{2}{*}{0.416} \\
\hline Female & $21 \pm 3.2$ & & & \\
\hline \multicolumn{5}{|l|}{ Marital status } \\
\hline Single & $20.5+3.9$ & \multirow[b]{2}{*}{0.045} & \multirow{2}{*}{0.356} & \multirow[t]{2}{*}{0.723} \\
\hline Married & $21.1+3$ & & & \\
\hline \multicolumn{5}{|l|}{ Qualification } \\
\hline Bachelor & $22.9+3.2$ & \multirow[b]{3}{*}{-0.285} & \multirow[b]{3}{*}{-2.132} & \multirow[t]{3}{*}{ 0.038* } \\
\hline Technical & $19.9 \pm 2.5$ & & & \\
\hline Diploma & $21.1 \pm 3.4$ & & & \\
\hline \multicolumn{5}{|l|}{ Years of experiences } \\
\hline $1-<5$ years & $19.8+2.9$ & \multirow{2}{*}{0.408} & \multirow{2}{*}{2.776} & \multirow[t]{2}{*}{$0.008 * *$} \\
\hline$\geq 5$ years & $21.9 \pm 3.1$ & & & \\
\hline
\end{tabular}

Table (4): Mean score distribution of studied nurses' practice regarding palliative care of cancer patients (No. $=60$ ).

\begin{tabular}{|l|c|c|}
\hline \multicolumn{1}{|c|}{ Nurses' practices } & Total score & Mean+SD \\
\hline Pain assessment and management & 12 & $5.8 \pm 1.2$ \\
\hline Nursing care for nausea and vomiting & 5 & $3.4 \pm 0.8$ \\
\hline Nursing care for oral mucositis & 6 & $2.9 \pm 0.7$ \\
\hline Nursing care for dyspnea & 4 & $3 \pm 0.1$ \\
\hline Communication skills & 6 & $4.7 \pm 1.2$ \\
\hline Total score of nurses' practices & 33 & $19.8 \pm 2.7$ \\
\hline
\end{tabular}




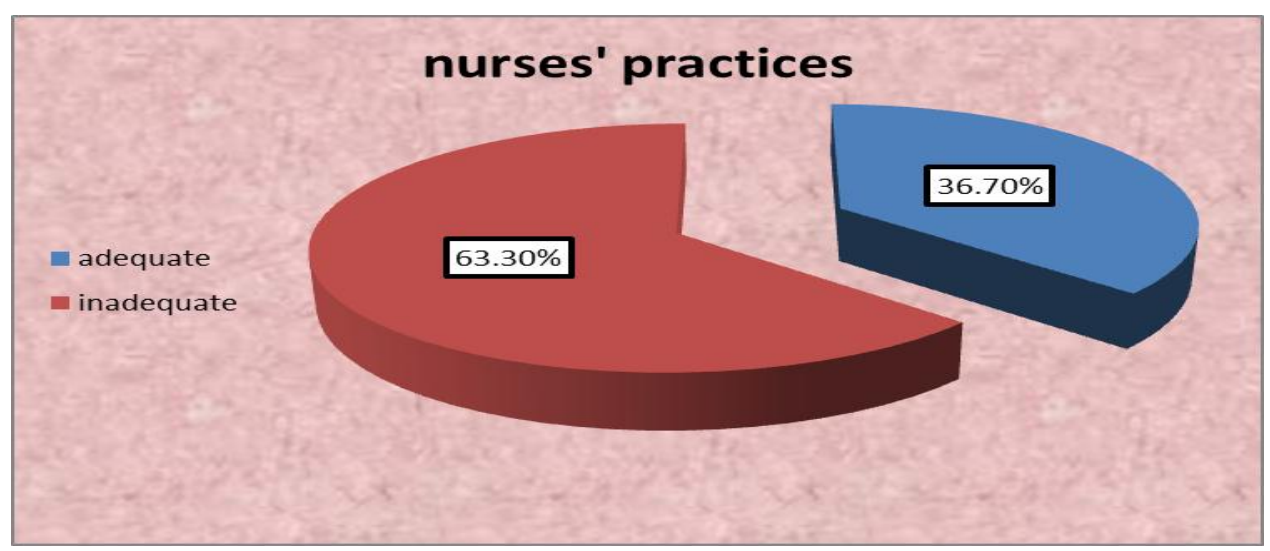

Figure (2): Percentages distribution of studied nurses' practices regarding total items of palliative care of cancer patients

Table (5): Relation between nurses' level of practices regarding palliative care and socio-demographic characteristic.

\begin{tabular}{|c|c|c|c|c|}
\hline socio-demographic data & Nurses' practices & Beta & $\mathbf{t}$ & P. value \\
\hline \multicolumn{5}{|l|}{ Age groups } \\
\hline $20-30$ years & $19.4 \pm 2.5$ & \multirow[t]{2}{*}{0.245} & \multirow[t]{2}{*}{3.22} & \multirow[t]{2}{*}{0.000 *** } \\
\hline $30-40$ years & $21.6 \pm 2.8$ & & & \\
\hline \multicolumn{5}{|l|}{ Sex } \\
\hline Male & $22.5 \pm 0.7$ & \multirow{2}{*}{-0.136} & \multirow{2}{*}{-1.080} & \multirow{2}{*}{0.285} \\
\hline Female & $19.7 \pm 2.7$ & & & \\
\hline \multicolumn{5}{|l|}{ Marital status } \\
\hline Single & $18.9+3$ & \multirow{2}{*}{0.045} & \multirow{2}{*}{0.351} & \multirow{2}{*}{0.727} \\
\hline Married & $20 \pm 2.6$ & & & \\
\hline \multicolumn{5}{|l|}{ Qualification } \\
\hline Bachelor & $18.9 \pm 2.7$ & \multirow{3}{*}{0.185} & \multirow{3}{*}{1.368} & \multirow{3}{*}{0.177} \\
\hline Technical & $19.3 \pm 2.6$ & & & \\
\hline Diploma & $20.6+2.7$ & & & \\
\hline \multicolumn{5}{|l|}{ Years of experiences } \\
\hline $1-<5$ years & $19 \pm 2.4$ & \multirow{2}{*}{0.212} & \multirow{2}{*}{2.11} & \multirow{2}{*}{ 0.039* } \\
\hline$>=5$ years & $20.4+2.8$ & & & \\
\hline
\end{tabular}

Table (6): Relation between nurses' knowledge and their practices level.

\begin{tabular}{|c|c|c|c|c|c|}
\hline \multirow{3}{*}{ Nurses' practices } & \multicolumn{4}{|c|}{ Knowledge survey regarding palliative care } & \multirow{3}{*}{ P. value } \\
\hline & \multicolumn{2}{|c|}{ Satisfactory } & \multicolumn{2}{|c|}{ Unsatisfactory } & \\
\hline & No. & $\%$ & No. & $\%$ & \\
\hline Satisfactory & 2 & 100.0 & 20 & 34.5 & \multirow{2}{*}{0.274} \\
\hline Unsatisfactory & 0 & 0.0 & 38 & 65.5 & \\
\hline
\end{tabular}

$<60 \%$ unsatisfactory

$\geq 60 \%$ satisfactory 
Table (1): shows socio-demographic characteristics of studied nurses. It observed that the majority of studied nurses $(81.7 \%)$ were at the age group of 20 to 30 with a mean age of $26.2+5.1$ and only $(18.3 \%)$ of studied nurses' age ranged had >30:40 years. As regarding sex the majority of studied nurses $(96.7 \%)$ were females. As regarding marital status the majority of studied nurses $(81.7 \%)$ were married. More than one third of studied nurses $(41.7 \%)$ were diploma degree in nursing, $(40.0 \%)$ of them had a technical degree in nursing, and $(18.3 \%)$ of them had a universal degree in nursing. The years of experiences of studied nurses less than 5 years were $(45.0 \%)$, 5years and more were $(55.0 \%)$.It observed that all of nurses $(100 \%)$ didn't receive training program about palliative care. (Figures from 6 to 10 show percentage distribution of studied nurses according to their socio-demographic characteristics)

Table (2): show nurses' knowledge about palliative care of cancer patients. It's apparent from this table that total knowledge score of palliative care of studied nurses were 46 with Mean+SD $21 \pm$ 3.2,knowledge about definition of palliative care and its principles, pain and symptoms' management, psychological issues and spiritual issues were with Mean \pm SD $(1 \pm 1,15.8 \pm 2.6,2.3 \pm 0.7$, and $1.9 \pm 0.9)$ respectively.

Table (3): show that there were statistically significant relation of knowledge of studied nurses and their qualification and years of experiences.

Table (4): show nurses' practices about palliative care of cancer patients. It's apparent from this table that total practices score of palliative care of studied nurses were 33 with Mean \pm SD $19.8 \pm 2.7$, practices about Pain assessment and management, nausea and vomiting , oral mucositis, dyspnea , and Communication skills were with Mean+SD $(5.8 \pm$ $1.2,3.4 \pm 0.8,2.9 \pm 0.7,3 \pm 0.1$, and $4.7 \pm 1.2)$ respectively.

Table (5): Demonstrated that there were statistically significant relation of practice of studied nurses and their age, and years of experiences.

Table (6): demonstrates that there were no statistically significant relation between practices and knowledge level of studied nurses.

\section{Discussion}

The scope of palliative care has expanded to include patients who may live for many years with end stage organ failure or cancer. Some chronically ill patients die from the side effect of treatment .One of the important factors influencing a successful delivery of palliative health care is the health care professionals' knowledge, attitudes, beliefs, and experiences, which determine not only their procedure but also their behavior during evaluation and treatment of patients. Nurses are the most valuable palliative care team members who address the physical, functional, social, and spiritual dimensions of care (Sanderson \& Tieman, 2010, Skar, 2010)

The aims of present study are 2 folds: assess knowledge and practices of critical care nurses regarding palliative care of cancer patients at intensive care units at South Egypt Cancer Institute, and suggest nursing guidelines booklet about palliative care for cancer patients.

This discussion will cover the main result findings as follow:

\section{Socio-demographic characteristics of studied} nurses

The results of the present study showed that the majority of studied nurses were at the age group between 20 to 40 years, females, and married, nursing diploma is the highest proportion, and more than half of nurses had years of experiences about 5 years and more. All of nurses didn't receive training program about palliative care. In my opinion that is may be due to that the younger nurses are those who get more involved in high complexity healthcare fields as intensive care units, and the majority of nurses were females that may be due to nursing school science along time were receive female more than male student that is might be the fact that females are patient and merciful than male.

This result also agree with (Bahza, 2013) who stated that "the majority of nurses were married; female, nursing diploma is the highest proportion, years of experiences more than 3 years., also (Mostafa, 2012); reveal that the majority of nurses their age ranged from $20-<30$ years, married; female, have nursing diploma, and their experiences ranged from 5to10 years. This result agrees with (Dedeli, et al., 2016) who found that $87.3 \%$ of nurses were women; the majority of them were married $(62.7 \%)$. The average age of the nurses was $31.9 \pm 7.2$ years, , and $80 \%$ of them their experiences were more than 5 years (David, \& Banerjee, 2010) revealed that Out of the 100 nurses only eight of them received specialized training in palliative care.

\section{Nurses' knowledge regarding palliative care}

The results of the present study showed that the majority of studied nurses had unsatisfactory knowledge scores regarding total items of palliative care. This could be due to that these nurses have not been trained on palliative care, limited attention to nurses' continuing education.

This result agrees with (Ayed, et al., 2015) who shown that only $20.8 \%$ of studied nurses had good knowledge score about palliativ, 2015)also agree with this result who showed that the majority of 
nurses (79\%) had unsatisfactory knowledge about palliative care.

Regarding what is palliative care, its principles the present study showed that the majority of the studied nurses had unsatisfactory general knowledge regarding definition of palliative care, its principles and timing, the results of the current study on the line with (Karkada1, et al., (2011) who revealed that the minority of studied nurses were aware of the definition palliative care.

As regard pain management it observed that all of studied nurses $(100 \%)$ had unsatisfactory knowledge about pain management that is may be due to lack of protocols and basic standard guidelines on pain assessment and management and nurses working with no specialization, on the same line with findings of current study Shahnazi, et al., (2012) revealed that the majority of nurses had insufficient knowledge regarding cancer pain management.

Regarding physical symptoms management and psychological issues the majority of studied nurses had satisfactory knowledge scores about nausea and vomiting management that may be due to the most frequent symptom for cancer patients is nausea and vomiting so nurses were familiar with it. The majority of studied nurses had unsatisfactory knowledge scores dyspnea management. Finding of current study agree with Radhika, \& Ongole, (2015) who revealed that majority $81(51.3 \%)$ of the staff nurses had poor knowledge of oral care in cancer patients. The majority of studied nurses $(90.0 \%)$ had satisfactory knowledge scores about Psychological issues that is may be due to the experiences and seniority nurses or they consider their work with cancer patients as meaningful and rewarding (Mazanec, etal. 2010) stated that all oncology patients will be affected in some way by their treatment. Structured assessment undertaken by oncology nurses enables us to identify patients at risk for poor adjustment early and can help to direct the use of interventions aimed at fostering a sense of optimism and ultimately improve health related quality of life during survivorship.

About three quarter of studied nurses had unsatisfactory knowledge scores about spiritual issues. Iranmanesh, et al., (2013) found that the lowest correct answers were in the category of spiritual care.

Approximately the same finding was indicated by (Morsy, et al., 2014) who revealed that the majority of the studied sample had unsatisfactory general knowledge; and unsatisfactory knowledge about physical symptoms requiring palliative care. However, they had satisfactory knowledge about psychological symptoms (Prem, et al., 2012) found that knowledge about pain was low, only less than
$35 \%$ of nurses had correct responses for knowledge subscale. Iranmanesh, et al., 2013 disagree with this finding who found that the most correct answers were in the category of management of pain and other symptoms (46.07\%). The lowest correct answers were in the category of psychosocial care $(19.3 \%)$.

Regarding relation between knowledge level regarding palliative care and socio-demographic characteristics of studied nurses the current study revealed that there is no significant relations between nurses total knowledge scores and age, sex, and marital status and there were significant statistical relationship was between qualification and years of experiences and nurses total knowledge scores that is may be due to that with elevation level of education the knowledge base increase, as well when increases year of experience increase amount of acquired knowledge. (Ayed, et al., 2015) found that there are no significant relations between knowledge scores towards, gender, academic level, personal and professional experience. At the same time, it was statistical significant relations with age. Findings of current study disagree with Karkada, et al., (2011) who revealed a significant association between the age of the nurses and their knowledge about palliative care, As well, Prem, et al., (2012) found that female nurses had slightly higher knowledge scores than male nurses.

\section{Nurses' practices regarding palliative care}

The results of the present study showed that more than half of studied nurses had unsatisfactory level of total practices score regarding palliative care of cancer patients that may be due to that nurses didn't receive definite training program about different aspect of palliative care the majority of studied nurses had unsatisfactory level of practice regarding pain assessment and management, that is may be due to that the nurses usually well concerned with obey command of doctor especially giving medication and neglected their nursing role as assessment of pain and non-pharmacological management of pain. As well, Bernardi, et al., (2007) showed that more than half of nurses underestimated the patients' pain and they did not manage it in the correct way.

As well, Baker, et al., (2013) conducted a study about satisfaction with pain treatment in older cancer patients, and revealed that there is a need for pain education to address misunderstandings and concerns in managing cancer pain.

As regarded Nursing care for dyspnea it was found that all of nurses had satisfactory level of practice that is may be attributed to due to the management line of dyspnea urgent, obvious and available.

More than half of studied nurses had satisfactory level of practice regarding nursing care for nausea and vomiting that is may be due to that the most 
common symptoms of cancer and effect of its treatment are nausea and vomiting so nurses manage them well. As regarded nursing care for oral mucositis it was found that the majority of nurses had unsatisfactory level of practice (Morsy, et al., 2014) revealed that the majority of the studied sample had unsatisfactory practice level. Assessment of nurses' practice was done regarding physical symptoms such as pain As regards to pain; nurses didn't assess pain using numerical or visual scales. Only on admission, they assessed the anatomical location of pain.

As regarded Communication skills it was found that more than three quarter of nurses had satisfactory level of practice that is may be due to Egyptian people general are kindful , patient and good listener. (Sorifa, Mosphea, 2015) showed that the practice score on communication' is moderately satisfactorye among the nurses.

The current study demonstrated that there were statistically significant relation of total practices of studied nurses and their age, and Years of experiences.in my opinion that is may be due to nurses with highest experiences have background that reflect on their practices than novice nurses . (Morsy, et al., 2014) agree with this result who found that, there was a significant statistical relation between years of experience and total mean practices scores, (Aydin, \& Karadağ, 2010) agree with this findings who found that Significant correlations between the percentage of correct answers and previous experience

The results of the present study showed that there was no statistically significant relation between practices and knowledge level of studied nurses that is may be due to the nurses didn't receive education program about palliative care but their skills had learned from field of work through practice. This may indicate that nurses carryout certain aspects of practices without knowledge base. This finding is disagreeing with the study done by (Abu- Saad, et al., 2009) who found that Knowledge scores were statistically associated with practice scores and degree.

\section{Conclusion}

Based on result of this study it can be concluding that: The general score of nurses' knowledge and practice related to the palliative care isn't enough; there were no statistically significant relation between knowledge of studied nurses and their practices.

\section{Recommendations}

- Updating knowledge and practice of ICU nurses through carrying out continuing educational programs about palliative care.
- Nursing curriculum should in co-operate progressive palliative care as health education to improve the nursing care of the staff nurses.

- Research should be continued on newer practices and method of palliative care. The study will serve as a valuable reference material for future investigations.

- Nurses should reading nursing guidelines booklet.

\section{References}

1. Abu- Saad H., Dimassia H., \& Abbouda S., (2009): Perspectives on palliative care in Lebanon: Knowledge, attitudes, and practices of medical and nursing specialties. Palliative and Supportive Care; 7:339-47. Available at: http://www.ncbi.nlm.nih.gov/pubmed/19788776, accessed at May 2009

2. American cancer society, (2015): a guide to palliative or supportive care available at: http://www.cancer.org/treatment/treatmentsandsi deeffects/palliativecare/supportive-care accessed at March 2015

3. Aydin A., Karadă A., (2010): Assessment of nurses' knowledge and practice in prevention and management of deep tissue injury and stage I pressure ulcer ,2010, National Library of Medicine available at http://www.ncbi.nlm.nih.gov/pubmed/20736857 accessed at February 2010

4. Ayed A., Sayej S., Harazneh L., Fashafsheh I., Eqtait F., (2015): Nurses' Knowledge and Attitudes towards the Palliative Care ,2015, Journal of Education and Practice , Vol.6, No.4, The pages222-224 ,ISSN 2222-1735 .

5. Bahza N., (2013): developing nursing care standard for partial fulfillment of the requirement of the master degree in medical surgical nursing, 2013, faculty of nursing, Assuit University, discussion part, pp57, 58

6. Baker, Tamara A., O'Connor, Melissa L., Roker, Rosalyn, Krok, Jessica L., (2013): Satisfaction with Pain Treatment in Older Cancer Patients: Identifying Variants of Discrimination, Trust, Communication, and Selfefficacy. $\quad$ Available at http://www.ncbi.nlm.nih.gov/pmc/articles/PMC3 867008/ more than half accessed at February 2013

7. Bernardi M., Catania G., Lambert A., Tridello G., Luzzani M., Knowledge \& attitudes about cancer pain management (2007): European Journal Oncology Nursing vol.11no.(3)page272.

8. British Columbia cancer agency, Advanced Cancer \& Palliative Care, (2016): available at 
http://www.bccancer.bc.ca/health-info/copingwith-cancer/advanced-cancer-palliative-care, accessed at February 2016

9. Canadian Virtual Hospice, (2015): what is palliative care? available at http://www.virtualhospice.ca/en_US/Main+Site+ Navigation/Home/Topics/Topics/What+Is+Pallia tive+Care_/What+Is+Palliative+Care_.aspx accessed at May 2015

10. Cancer Care Ontario, Impact of Cancer, (2012): available at http://ocp.cancercare.on.ca/impact/ accessed at September 2012

11. Carpenito L., Nursing Care Plan Transitional Nursing \& Family Centered Care, (2014): 6 ed., Williams and Wilkins Company, New York, chapter6, pages 623,635.

12. Center of disease control \& prevention, International Cancer Control, (2014): available http://www.cdc.gov/cancer/dcpc/resources/featur es/WorldCancerDay/ accessed at September 2014

13. David A., Banerjee S., Effectiveness of "palliative care information booklet" in enhancing nurses' knowledge, (2010): Indian Journal of palliative care, Volume: 16, no.: 3 Page: 164-167

14. Dedeli O., Daban U., Pakyuz S., Turkish Nurses' Attitudes towards Patients with Cancer,(2016): International Journal of Nursing ScienceV6,No7,pages1-6.

15. International Agency for Research on Cancer, Globocan, (2012): Estimated Cancer Incidence, Mortality and prevalence Worldwide.

16. Karkadal S., Nayak B., Malathi, Awareness of palliative care among diploma nursing students, (2011): Page: $20-23$.

17. Lewis, Dirksen, Heitkemper, Bucgeretal, (2015): Lewis's Medical Surgical Nursing, $2^{\text {nd }}$ edition, , El Sevier, India, page 138,270.

18. Mazanec S., Daly, B., Douglas, S. \& Lipson, A., (2010): the relationship between optimism and quality of life in newly diagnosed cancer patients. Cancer Nursing, 33(3):235-243.

19. Morsy W., Elfeky H., Mohammed S., (2014): Nurses' Knowledge and Practices about Palliative Care among Cancer Patient in a University Hospital, Advances in Life Science and Technolog, Vol.24,no2,page235.

20. Morton, P., Fontaine, D., (2013): Essentials of Critical Care Nursing a Holistic Approach, , 10 ${ }^{\text {ed }}$, Wolters Kluwer/Lippincott Williams \& Wilkins, London, chapter 6, pages41-45.

21. Mostafa, (2012): developing standard of postoperative nursing intervention for lower limb amputated patient for partial fulfillment of the requirement of the master degree in medical surgical nursing.

22. Nyakundi A., (2013): A nurse's role in palliative care available at https://www.ehospice.com/kenya/tabid/10674/Ar ticleId/4632/language/en-GB/View.aspx accessed at February 2013.

23. Potter, A., Perry, A., Stockert P., Hall A., Basic nursing, (2011): Mosby company, Canada $7^{\text {ed }}$, chapter25, page668-669, ,.

24. Prem V., Karvannan H., Kumar S., Karthikbabu S., et al., (2012), Study of Nurses' Knowledge about Palliative Care: A Quantitative Cross-sectional Survey, Indian Journal of Palliative Care,18(2): pages122-127

25. Radhika R., \& Ongole R., (2015): Nurses' Knowledge and Education about Oral Care of Cancer Patients Undergoing Chemotherapy and Radiation Therapy, Indian Journal of Palliative Care, v.21(2);page 122,

26. Sanderson C., Tieman J., (2010): Care Searchonline palliative care information for GPs. Aust Family Physician, 39, 341-3

27. Shahnazi H., Saryazdi H., Sharifirad G., Hasanzadeh A., et al., (2012): The survey of nurse's knowledge and attitude toward cancer pain management, Journal of Education and Health Promotion, V.1,no/15,page 45.

28. Skar R., (2010): Knowledge use in nursing practice: The importance of practical understanding and personal involvement. Nurse Education Today; 30:132-6.

29. Sorifa B., Mosphea K., (2015): Knowledge and Practice of Staff Nurses on Palliative Care, IJHRMLP, Vol: 01 No: 02, (Page41-45)

30. South Egypt Cancer Institute, (2014): Hospital records.

31. World cancer research fund International, (2013): worldwide data, available at http://www.wcrf.org/int/cancer-factsfigures/worldwide-data

32. World health organization, (2014): Cancer, available http://www.who.int/mediacentre/factsheets/fs297 /en/ accessed at March 2014 